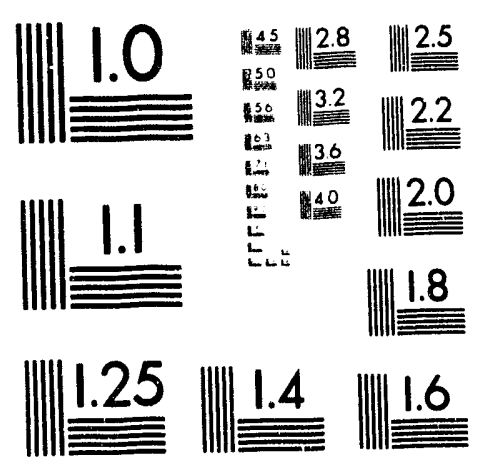



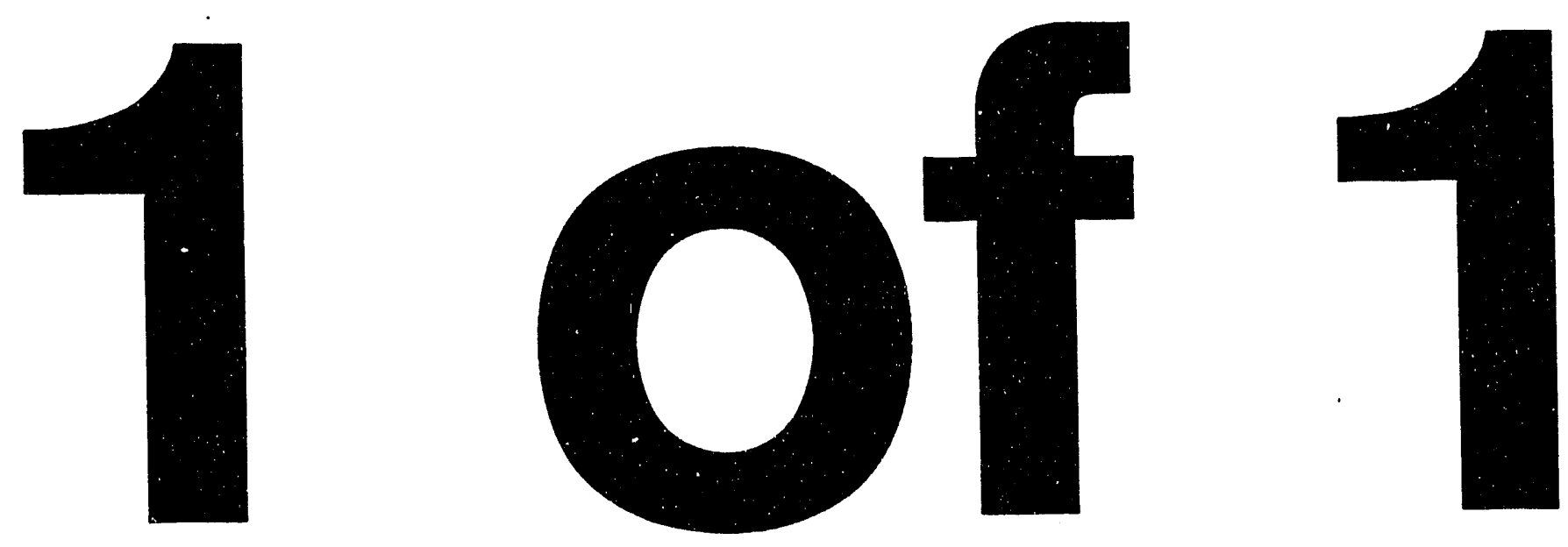


\section{Y-12}

\section{OAK RIDGE \\ Y-12 \\ PLANT}

MARTIN MARIETRA

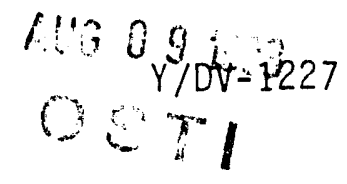

INVESTIGATION OF CRACKING AND ERRATIC BEHAVIOR OF THE URANIUM-TITANIUM ALLOY

\author{
E. L. Bird
}

Materials Engineering Department Development Division

Date of Issue: July 7, 1993

\author{
For oral presentation at \\ International Metallographic Society Meeting \\ Charleston, South Carolina \\ JuTy 18-21, 1993
} managed by

MARTIN MARIETTA ENERGY SYSTEMS, INC. for the

U.S. DEPARTMENT OF ENERGY

under contract DE-ACO5-840R21400 


\section{DISCLAIMER}

This report was prepared as an account of work sponsored by an agency of the United States Government. Neither the United States Government nor any agency thereof, nor any of their employees, makes any warranty, express or implied, or assumes any legal liability or responsibility for the accuracy, completeness, or usefulness of any information, apparatus, product, or process disclosed, or represents that its use would not infringe privately owned rights. Reference herein to any specific commercial product, process, or service by trade name, trademark, manufacturer, or otherwise, does not necessarily constitute or imply its endorsement, recommendation, or favoring by the United States Government or any agency thereof. The views and opinions of authors expressed herein do not necessarily state or reflect those of the United States Government or any agency thereof.

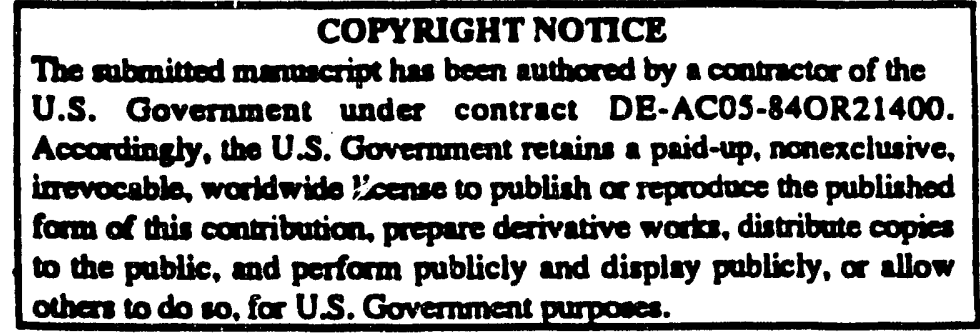




\title{
INVESTIGATION OF CRACKING AND ERRATIC BEHAVIOR OF THE URANIUM-TITANIUM ALLOY
}

\author{
E. L. Bird ${ }^{1}$
}

\begin{abstract}
The uranium-0.8 wt \% titanium (U-0.8 Ti) alloy is often used in weapon applications where high strength and fairly good ductility are necessary. Components are immersion quenched in water from the gamma phase to produce a martensitic structure that is amenable to aging. Undesirable conditions occur when a component occasionally cracks during the quenching process, and when tensile specimens fail prematurely during mechanical testing. These two failures prompted an investigative analysis and a series of studies to determine the causes of the cracking and erratic behavior observed in this alloy. Quench-related failures whereby components that cracked either during or immediately after the heat treatment/quenching operation were sectioned for metallographic examination of the microstructure to examine the degree of phase transformation. Examination of premature tensile specimen failures by scanning electron microscopy and X-ray imaging of fracture surfaces revealed pockets of inclusions at the crack origins. In addition, tests were conducted to evaluate the detrimental effects of internal hydrogen on ductility and crack initiation in this alloy.
\end{abstract}

'Materials Engineering Department, Development Division, Oak Ridge Y-12 Plant, Oak Ridge, Tennessee (managed for the U. S. Department of Energy by Martin Marietta Energy Systems, Inc., under contract DE-AC05-840R21400). 


\section{INTRODUCTION}

Components requiring a combination of high strength and reasonably good ductility are often made from the uranium-0.8 wt \% titanium (U-0.8 Ti) alloy. Typically, these alloys are processed by vacuum solution heat treating above $723^{\circ} \mathrm{C}$ ( $\gamma$-phase), quenching in water to produce a martensitic structure ( $\alpha^{\prime}$-phase), and aging above $300^{\circ} \mathrm{C}$ to achieve desired mechanical properties. Typical mechanical properties for aged U-0.8Ti are provided in Table 1.

Table 1. Typical Properties of Aged Uranium- 0.8 wt \% Ti

\begin{tabular}{lr}
\hline Ultimate tensile strength & $1500 \mathrm{MPa}$ \\
Yield strength & $965 \mathrm{MPa}$ \\
Total elongation & $18 \%$ \\
Fracture toughness $\left(\mathrm{K}_{\mathrm{IC}}\right)$ & $50 \mathrm{MPa} \times \mathrm{m}^{3 / 2}$ \\
Fardness (1000-g load) & $420 \mathrm{dph}$ \\
Density & $18.5 \mathrm{~g} / \mathrm{cc}$ \\
\hline
\end{tabular}

During the quenching operation, the material is quenched from a body centered cubic crystallographic structure with titanium in solution to an orthorhombic structure consisting of $\alpha^{\prime}$-martensite that is supersaturated with titanium. Fine precipitates identified as $\mathrm{U}_{2} \mathrm{Ti}$ ( $\delta$ phase) are eventy dispersed throughout the matrix [1]. However, to obtain a complete $(100 \%)$ transformation to martensite, a cooling rate of $200^{\circ} \mathrm{C} / \mathrm{s}$ is required. This task is difficult to accomplish, often leading to the formation of a duplex structure consisting of the $\alpha^{\prime}$-martensitic phase and the $(\alpha+\delta)$ phase. During the aging process, the $\alpha^{\prime}$-martensitic phase responds more favorably than the $(\alpha+\delta)$ phase to produce the desired mechanical properties shown in Table 1 [2]. Occasionally, a component will craci: either during or immediately following the quench, which is a full immersion quench in water. Cracked components were sectioned and prepared for metallographic examination of the regions near the fractures.

Tensile specimens are prepared from aged components to determine if the mechanical properties meet specified requirements. Occasionally, one of the three tensile specimens taken from the component produced a total elongation value that was sutstantially lower than the elongation values of the companion specimens taken from the same component. When one of these "premature" failures occurred, both ends of the fractured tensile specimen were examined with the scanning electron microscope (SEM) to characterize the fracture surface. Some of these failed specimens were sectioned for metallographic evaluation and correlated with the SEM results.

Hydrogen, which can cause the embrittlement of U-0.8Ti, was also included in a series of studies designed to determine the role that absorbed hydrogen played in the erratic behavior of this alloy [3]. The primary source of hydrogen is the molten carbonate salt bath used for preheating the alloy before metalworking operations. Hydrogen absorbed from the salt bath can be removed by outgassing in a vacuum or argon during the solution heat treatment process. 


\section{EXPERIMENTAL PROCEDURES}

\section{Quench-Related Cracking}

No special experimental procedures were associated with the investigation of components that cracked during the heat treat/quench step of the process. When cracking did occur, the cracks were large and readily visible. The cracked components were sectioned near the primary fracture surface and prepared for metallographic evaluation. Those sections were polished and electrolytically etched in a solution prepared by adding $5 \mathrm{~g}$ of oxalic acid to $95 \mathrm{~mL}$ of water.

\section{Premature Tensile Failures}

Tensile specimens with a $16.25-\mathrm{mm}$ gage length $\times 4.06-\mathrm{mm}$ gage diameter are tested according to ASTM E-8, which limited the maximum crosshead velocity to $12.7 \mathrm{~mm} / \mathrm{mm}$ of gage length per minute [4]. Tensile failures that resulted in total elongation values $<16 \%$ were examined with SEM to characterize the fracture surfaces. Metallography and $\mathrm{X}$-ray imaging were also performed on some of these same failures to assist in the investigation and characterization of fracture morphologies and inclusions. In addition, a study was initiated whereby a machined-in "flaw," approximating the size of a large inclusion cluster, was introduced into the specimen and tested to determine the impact on mechanical properties.

\section{Hydrogen Effects}

Studies were initiated to determine the effects of different levels of absorbed hydrogen and differences in the crosshead velocity (strain rate). Reference test material was prepared by solution heat treating in vacuum for $1 \mathrm{~h}$, whereas the low-hydrogen test group was solutionized for $8 \mathrm{~h}$. Half of the tensile specimens taken from these test components were tester according to the current procedure, which specifies an initial speed of $1.27 \mathrm{~mm} / \mathrm{min}$ until yield reaches $0.85 \%$ extension under load (EUL), at which time the speed is increased to $3.81 \mathrm{~mm} / \mathrm{min}$. The other tensile specimens were pulled similarly, except that the crosshead velocity was increased to $8.128 \mathrm{~mm} / \mathrm{min}$ after reaching $0.85 \%$ EUL. The approximate strain rates for crosshead speeds of 3.81 and $8.128 \mathrm{~mm} / \mathrm{min}$ for the $16.25-\mathrm{mm}$ gage length are on the same order of magnitude $\left(10^{-3} / \mathrm{s}\right)$ but with a slight increase factor of approximately two. Mechanical properties data were collected and fractures were characterized using SEM and metallography.

\section{RESULTS}

\section{Quench-Related Cracking}

A section of one of the components that cracked during and/or following the quenching process is shown in Fig. 1. The amount of $\alpha^{\prime}$ martensite is estimated to be $<50 \%$, which is indicative of a cooling rate $<50^{\circ} \mathrm{C} / \mathrm{s}$. Other cracked components resulted in the same findings, except for one component that exhibited a martensitic structure that was predominantly $\alpha^{\prime}$ martensite. This finding was inconsistent with the other cracked components that clearly demonstrated an ineffective quench. The crack origin could not 
be determined primarily because of the heavily oxidized fracture surface. However, a region (shown in Fig. 2) near the original fracture surface revealed a crack emanating from a surface pit.

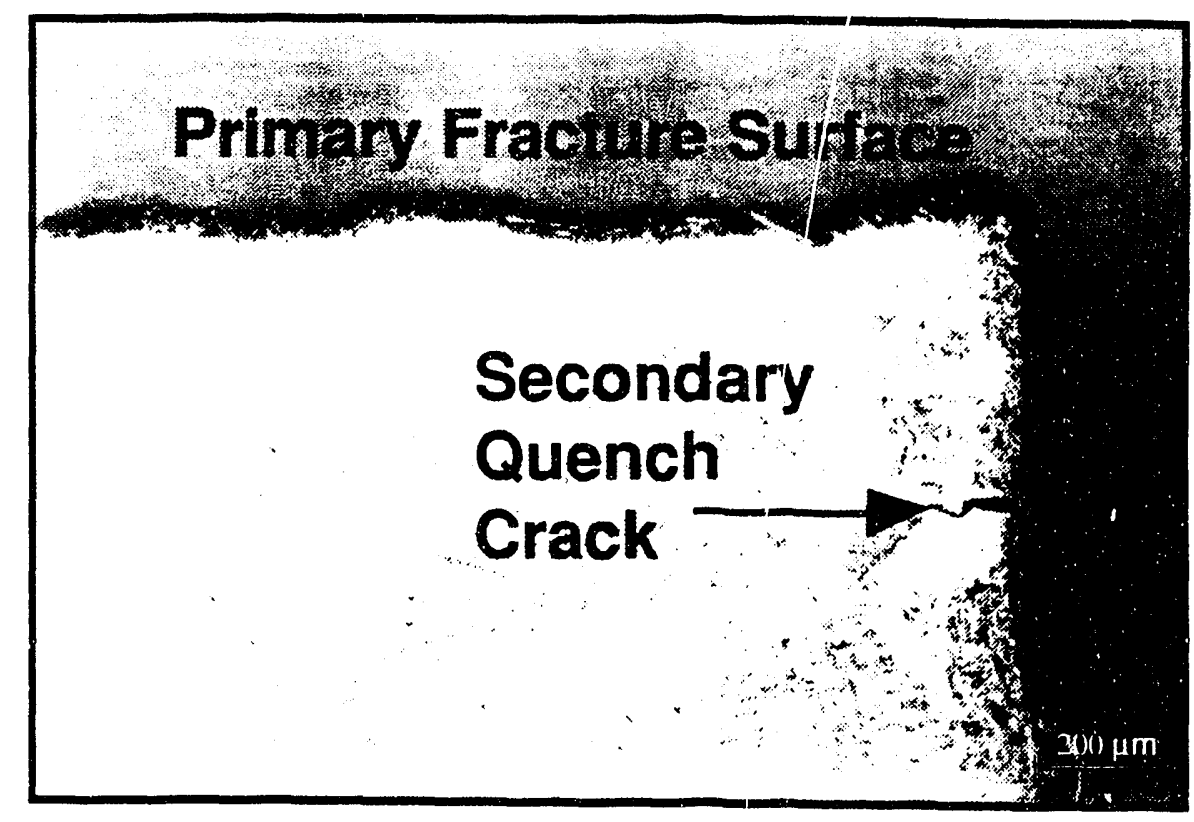

Figure 1. Microstructure of component that cracked during quenching. Phase transformation from $\gamma$ to $\alpha^{\prime}$ martensite was incomplete and indicative of cooling rate $<50^{\circ} \mathrm{C}$. 


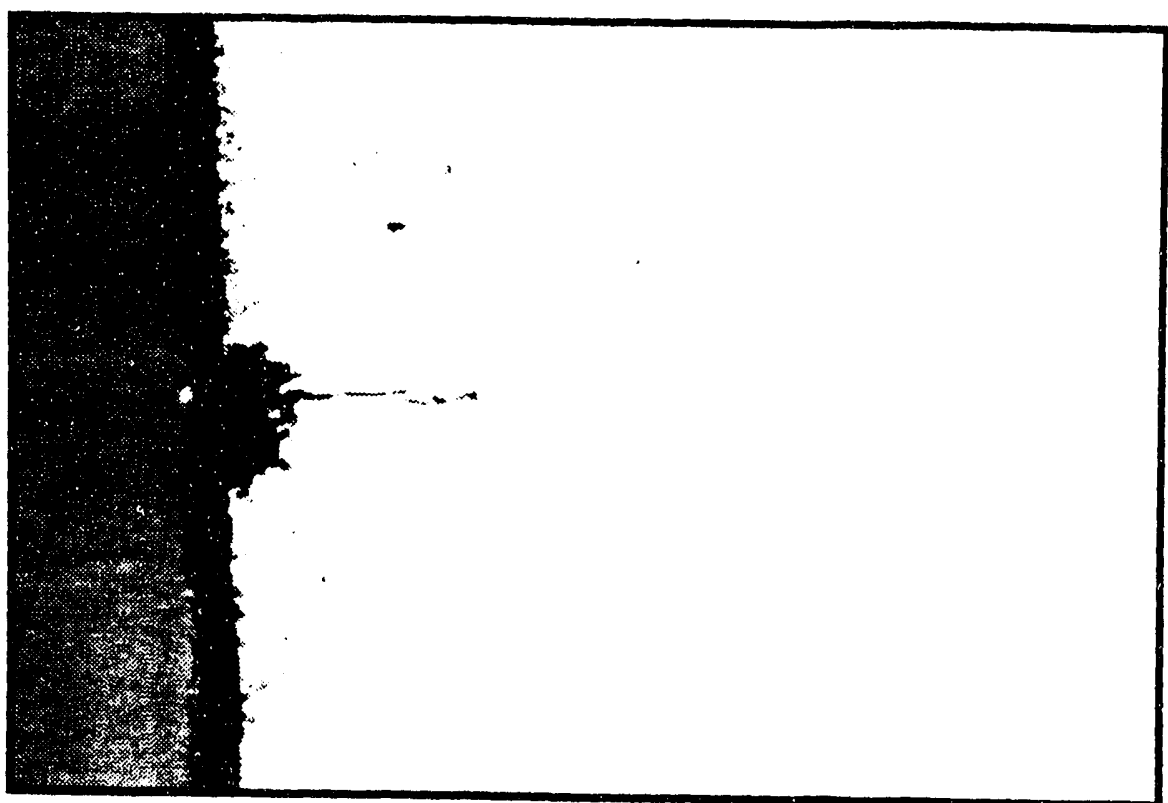

Figure 2. Secondary crack initiation at pit-like defect in microstructure that represents an effective quench yet component cracked.

\section{Premature Tensile Failures}

A pattern began to develop for tensile specimen failures that resulted in elongation values $<16 \%$. SEM evaluation of these tensile specimen fractures revealed inclusions, usually in clusters, at the crack initiation site, as shown in Fig. 3. Energy X-ray dispersive analyses of these clusters indicated chemistries that were higher in titanium than the surrounding matrix material. Figure 4 shows a typical example of a high-titanium peak. of the presence of titanium carbides, a cross section of the tensile specimen fracture surface was prepared for $\mathrm{X}$-ray imaging to confirm the presence of carbides. During the metallographic evaluation of the failed tensile specimen, materia material. Composite X-ray imaging techniques identified these inclusions (shown in Fig. 5) as titanium-rich on the left and carbon-rich on the right, which is indicative of titanium carbides. Elemental and composite images of the fracture surface, shown in Fig. 6 , confirmed the presence of both carbides and oxides.

To test the theory that inclusion clusters were the primary cause of erratic ductile values, a flaw (shown in Fig. 7) was machined into tensile specimens and tested at two levels of internal hydrogen content and two different strain rates. These results, which are shown in Table 2 , showed a $50 \%$ reduction in elongation in the notched specimens with no
appreciable effect on strength. 


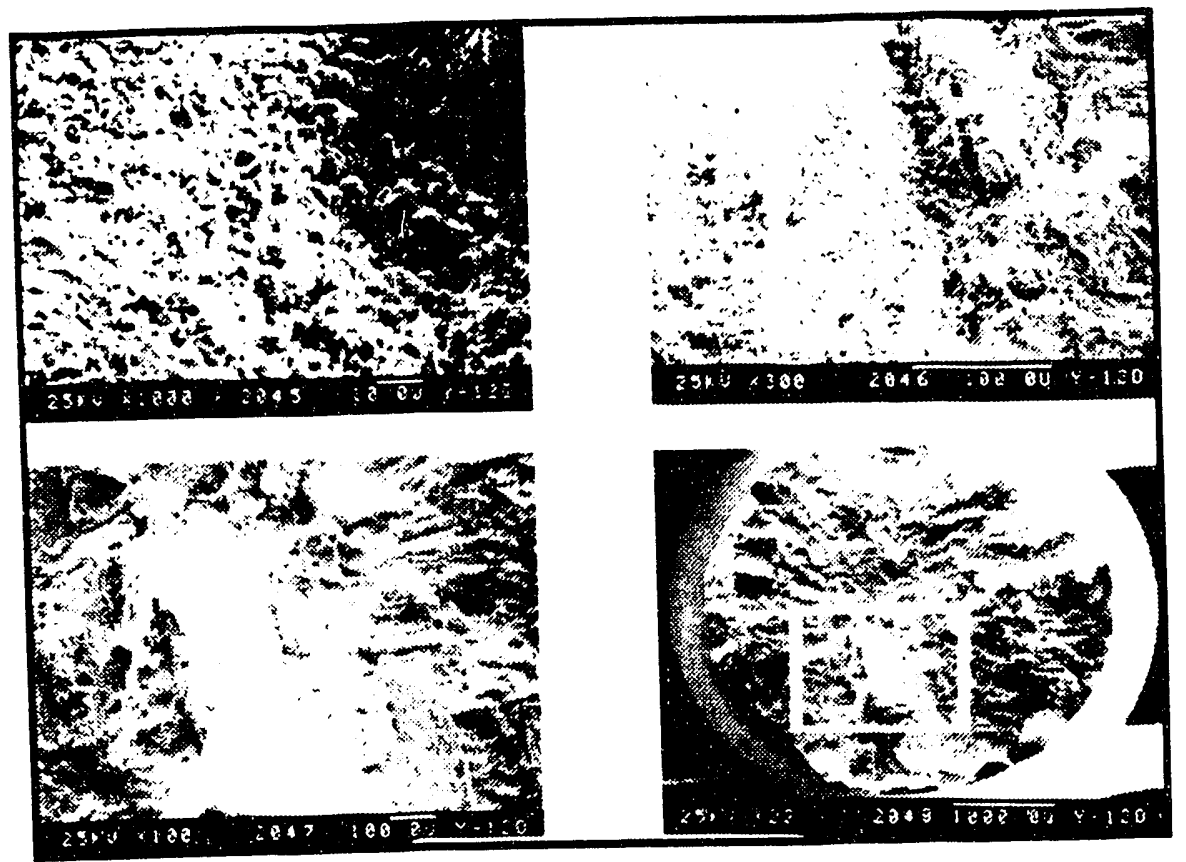

Figure 3. Subsurface inclusion cluster of tensile specimen with $7 \%$ elongation.

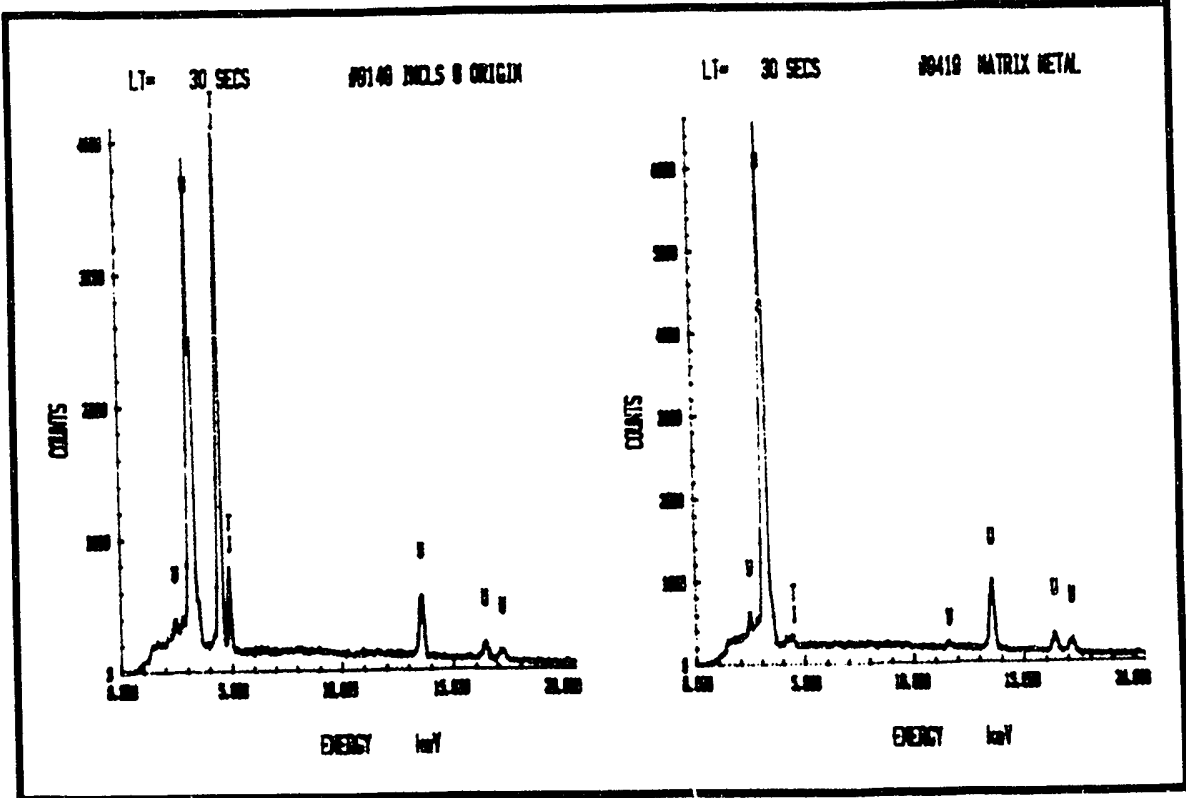

Figure 4. Energy dispersive X-ray spectra of titanium-rich inclusions at fracture origin. 


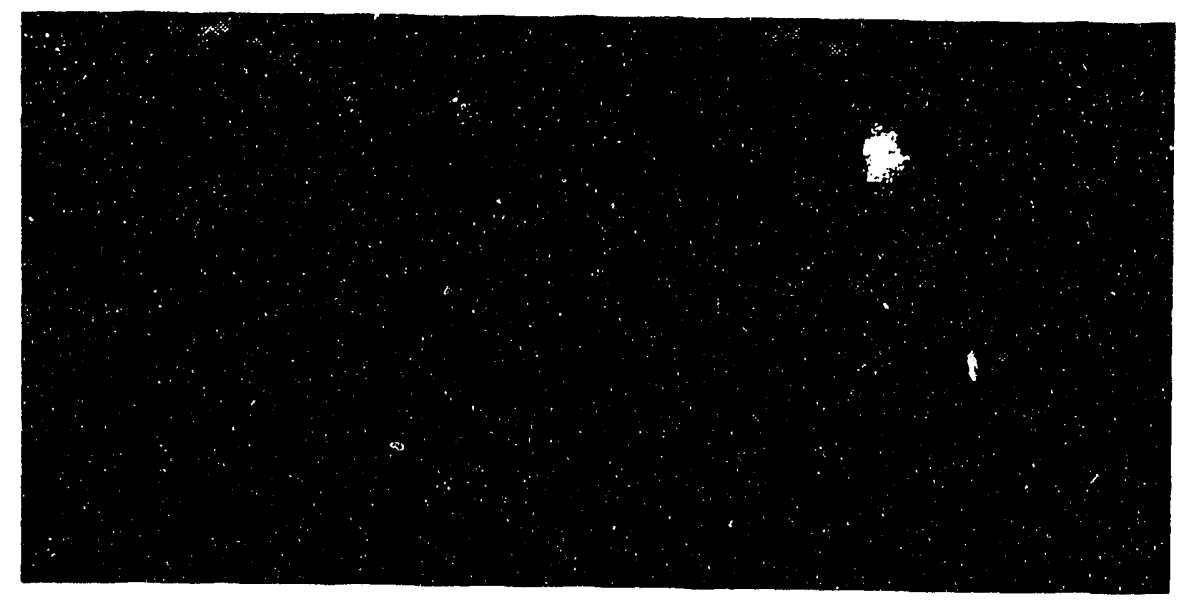

Figure 5. Composite $X$-ray imaging of inciusions adjacent to the internal crack that were identified as titanium carbides.

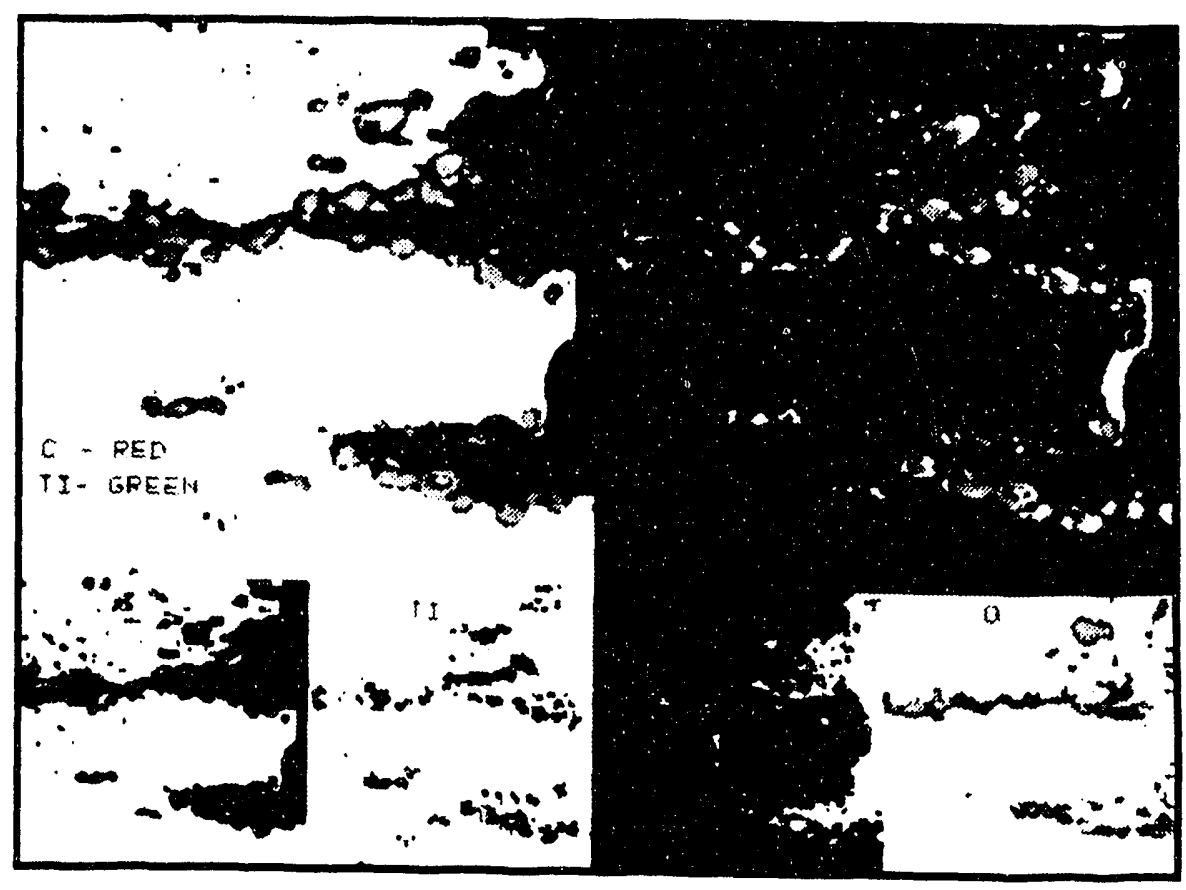

Figure 6. Elemental and composite images of inclusion cluster identified as titanium carbides on left and uranium oxides on right along the fracture surface. 


\section{DIMENSIONS $(0.23 \mathrm{~mm} \times 2.13 \mathrm{~mm} \times 0.53 \mathrm{~mm})$}

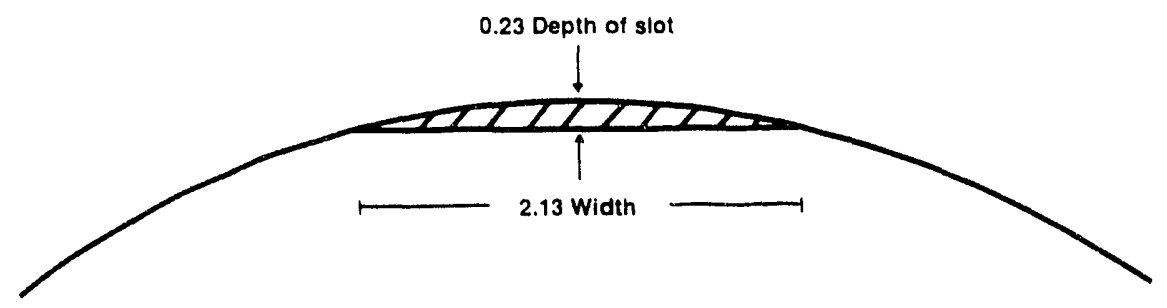

Figure 7. Geometry of notch machined into tensile specimen to simulate surface defect.

Table 2. Effect of Notch on Mechanical Properties

\begin{tabular}{lcc}
\hline & Smooth & Notched \\
\cline { 2 - 3 } & 1525 & 1450 \\
Ultimate tensile strength (MPa) & 890 & 919 \\
Tensile yield strength (MPa) & 22.7 & 9.6 \\
Total elongation (\%) & 27.7 & 10.1 \\
Reduction in area (\%) & \\
\hline
\end{tabular}

\section{Hydrogen Effects}

Material that was outgassed (vacuum solution heat treated) for $1 \mathrm{~h}$ resulted in an internal hydrogen level of $0.36 \mathrm{ppm}$, whereas material that was outgassed for $8 \mathrm{~h}$ resulted in $0.02 \mathrm{ppm}$ hydrogen. Tensile specimens taken from these two test groups were pulled at two different speeds by varying the crosshead velocity, which in effect, changes the strain rate. Table 3 shows these results. No significant differences in strength resulted from either hydrogen or strain rate. However, the effects of both hydrogen and strain rate on ductile properties is evident, as shown in Fig. 8. Fracture morphologies associated with each test condition revealed mixed fracture modes with slightly more microvoid coalescence observed in the test group with lower hydrogen content. In addition, secondary cracking (shown in Fig. 9) was observed in the higher hydrogenated specimens. 
Table 3. Effects of Hydrogen and Strain Rate on Mechanical Properties

\begin{tabular}{lcccc}
\hline & $\begin{array}{c}\text { High } \mathrm{H}_{2} \\
\text { (slow) }\end{array}$ & $\begin{array}{c}\text { High } \mathrm{H}_{2} \\
\text { (fast) }\end{array}$ & $\begin{array}{c}\text { Low } \mathrm{H}_{2} \\
\text { (slow) }\end{array}$ & $\begin{array}{c}\text { Low } \mathrm{H}_{2} \\
\text { (fast) }\end{array}$ \\
\cline { 2 - 5 } & 1532 & 1521 & 1525 & 1530 \\
Ultimate tensile strength (MPd) & 965 & 972 & 967 & 965 \\
Tensile yield strength (MPa) & 14.0 & 17.5 & 21.4 & 21.1 \\
Total elongation (\%) & 15.3 & 23.2 & 33.9 & 38.2 \\
Reduction in area (\%) & & & \\
\hline
\end{tabular}

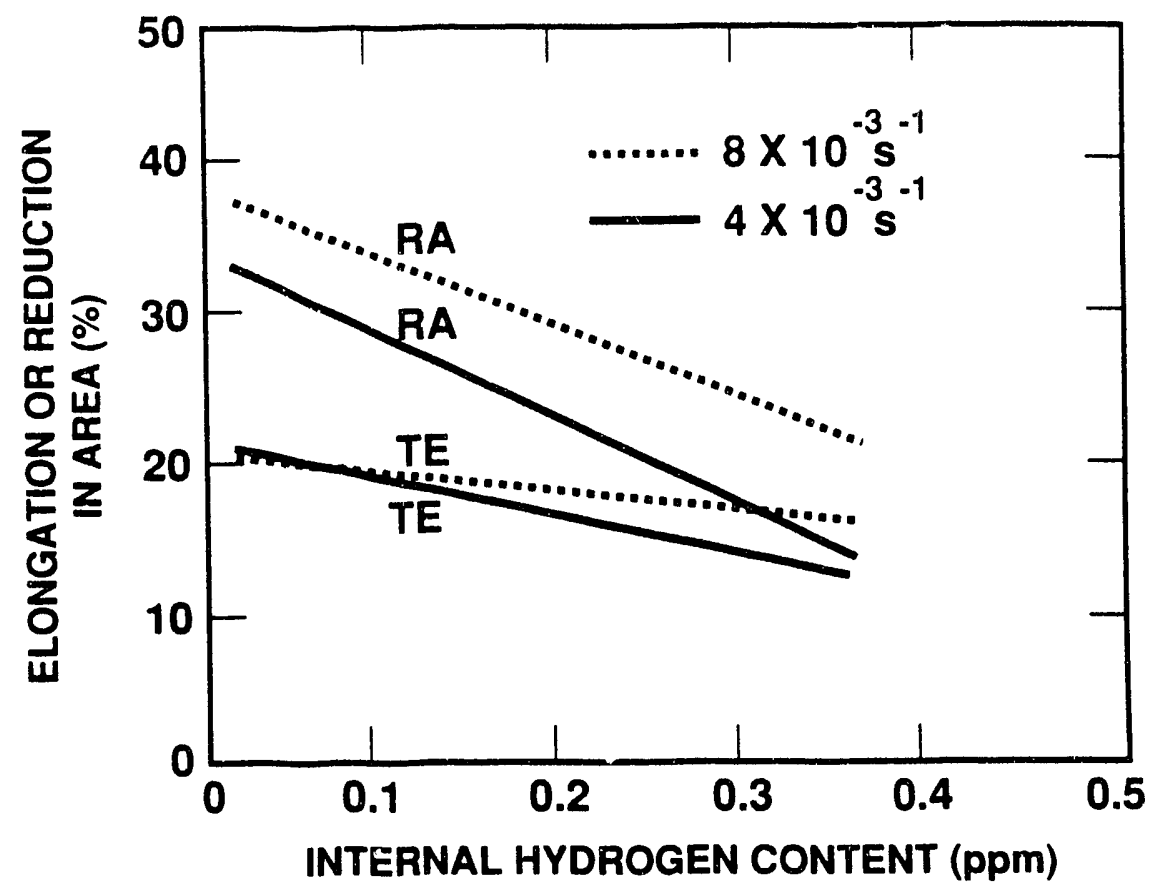

Figure 8. Ductility versus hydrogen content for aged uranium-0.8 titanium tested at two strain rates. 


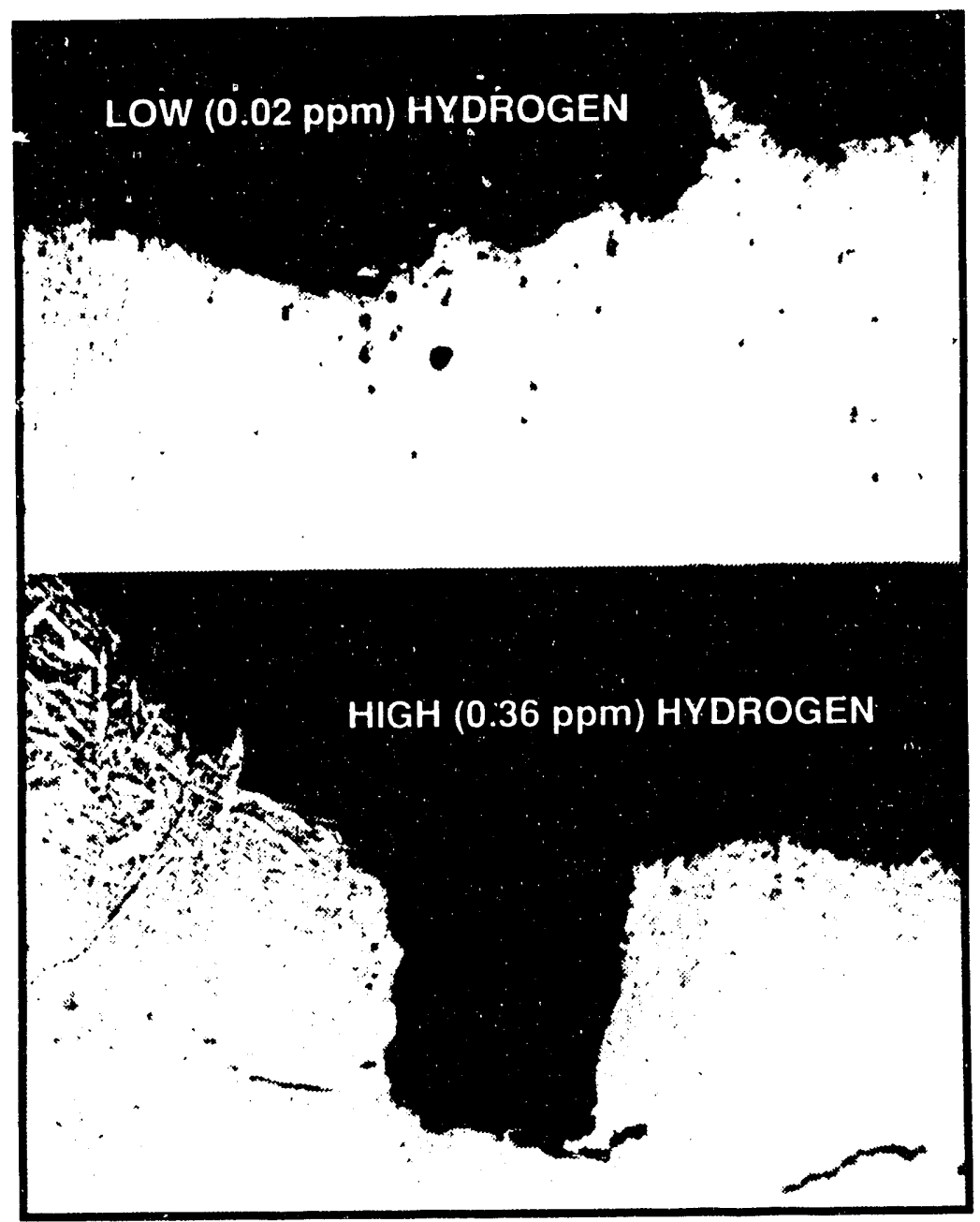

Figure 9. Fracture paths associated with predominantly ductile failure through martensitic platelets (above) and brittle, mixed mode along martensitic platelets (below). Also, in bottom photograph note secondary cracking observed in higher hydrogen specimen.

\section{DISCUSSION}

All but one of the components that cracked as a result of the quenching process exhibited a sluggish phase transformation indicative of a cooling rate $<50^{\circ} \mathrm{C} / \mathrm{s}$. The exception to this observation revealed a predominantly martensitic microstructure 
representative of a good quench. Obviously, stresses created during the quench operation exceeded the yield strength of the component to cause cracking. In fact, residual stresses were measured for quenched U-0.8Ti material and were very high, in some cases approaching or exceeding that of the yield strength [5]. These residual stresses were determined to be primarily the result of thermal gradients associated with asymmetricai quenching. The remaining quenched-in residual stresses are induced by differences in the yield strengths between the product phases and the volume contractions caused during the phase transformation. The presence of a defect in the form of a pit observed in the effectively quenched failure provides a clue that, even with complete phase transformation, the presence of a stress raiser and high residual stresses presents an ideal environment for crack nucleation. In all likelihood, the stress raiser in this case was a large inclusion cluster or another pit.

The effect of a notch or inclusion cluster on ductile properties is evident from the notched tensile specimen study. Some of the larger inclusion clusters observed in premature tensile specimen failures were similar in size to the simulated flaw. The size of the inclusion cluster appeared to be related to the elongation value. Some of the smaller inclusion clusters or isolated pockets of inclusions resulted in higher ductile properties but still fell short of the specified requirements.

Absorbed hydrogen is detrimental in several ways. First, specimens with higher levels of hydrogen averaged lower ductile values than specimens with lower hydrogen content. The role of hydrogen becomes more complicated in the presence of inclusion clusters and slower strain rate conditions. The preponderance of erratic ductile behavior observed in the specimens with higher hydrogen content and tested at the slower strain rate appears to be based on a strong correlation with inclusions. This phenomenon might be explained by the following theory.

An inclusion cluster or notch serves as an excellent site for crack nucleation, especially in this alloy, which is sensitive to hydrogen embrittlement. As a tensile load is applied, a triaxial stress field is created in the vicinity of the defect. Hydrogen atoms, present as absorbed hydrogen in the alloy, migrate toward and into the triaxial stress zone. As a sharp crack begins to emanate from the inclusion cluster discontinuity, the triaxial stress field becomes more intense, resulting in even greater migration of hydrogen atoms. The region immediately preceding the sharp crack tip becomes more saturated with hydrogen, primarily in the form of hydrides $\left(\mathrm{UH}_{3}\right)$, thereby causing local embrittlement and a lowering of the threshold stress intensity for subsequent crack growth. Figure 10 is an illustration of a theoretical model depicting this mechanism. 

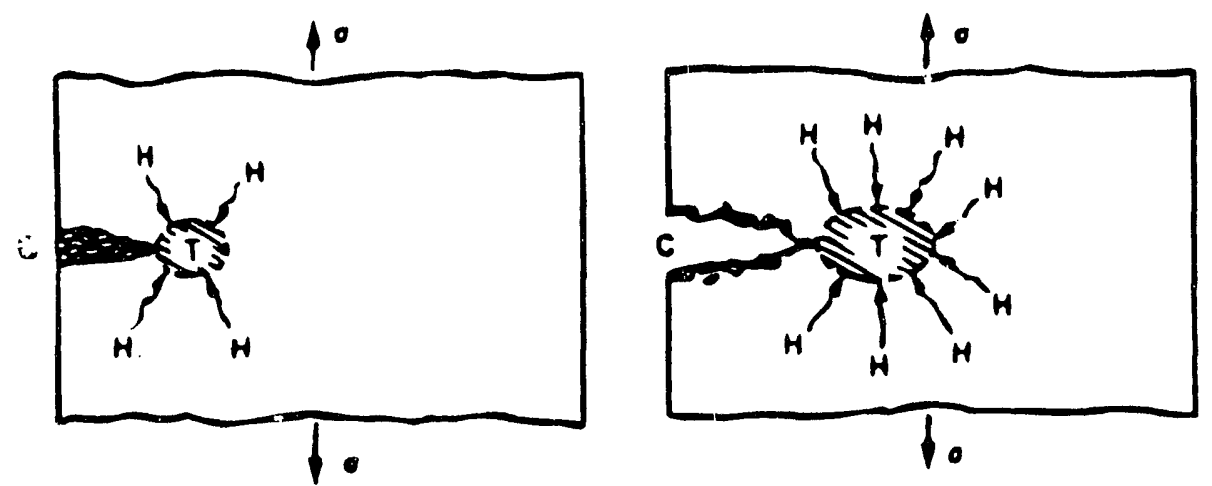

Figure 10. Theoretical model of hydrogen-assisted crack originating at inclusion cluster. (Left) Uniaxial load $(\sigma)$ applied to tensile specimen with inclusion cluster (C) at surface. Triaxial stresses $(T)$ develop at tip of inclusion cluster as hydrogen $(\mathrm{H})$ migrates to stressed region (T). (Right) Crack propagates into matrix as more hydrogen $(\mathrm{H})$ migstes to region of triaxial stresses ( $T$ ) immediately in front of crack tip.

The concept of hydrogen migration to regions of concentrated stresses was originally proposed by Troiano and coworkers but could not be demonstrated because of the tendency of hydrogen to redistribute when the load was removed $[6,7]$. However, efforts to measure hydrogen redistributions in a titanium-vanadium alloy were successful under plain strain conditions using nuclear reaction analysis [8]. Robinson et al., used tritium, which is the radioactive isotope of hydrogen that decays to helium, to demonstrate the concept of hydrogen isotope concentration enhancement at the tip of a blunt notch in the titanium-molybdenum alloy [9]. Another explanation that may be more applicable to inclusion clusters is the interaction between hydrogen and trap sites, as postulated by Pressouyre, et al. [10]. A basic assumption of the trap theory is that a crack will initiate on a given defect if the quantity of trapped hydrogen exceeds a critical concentration. This critical concentration depends on a number of variables, including defect shape, grain boundary coherency, applied stress, temperature, and impurities present at the defect-matrix interface. Indeed, the correlation of inclusion clusters and erratic ductile behavior was much more pronounced in the specimens with more hydrogen but only at the slower strain rate.

Fracture morphology also seems to be dependent on hydrogen content and strain rate. At slower strain rates, material with more abundant hydrogen has more time to migrate in larger quantities in the affected plastic zone immediately in front of the crack tip. Crack propagation along the martensitic platelet boundaries produces a brittle appearance that is characterized as predominantly quasi-cleavage. 


\section{CONCLUSIONS}

The results of the failure analyses and studies described in this report lead to the following conclusions.

1. Catastrophic cracking observed during or immediately following the quenching operation is caused by residual stresses resulting primarily from thermal gradients and secondarily by volume contractions associated with the phase transformation. In most cases, this condition, which is indicative of asymmetrical cooling can be observed by differences in the microstructure. Microstructures exhibiting only about $50 \% \alpha^{\prime}$-martensite are indicative of cooling rates $<50^{\circ} \mathrm{C}$ and are prone to degradation in mechanicil properties.

2. Premature tensile specimen failures are caused by inclusion clusters, which are evident at the specimen fracture origin. These inclusions are either titanium carbides or uranium oxides, and are often found in combination. Even with low levels of internal hydrogen (i.e., $<0.1 \mathrm{ppm}$ ), large inclusion clusters can cause premature cracking with a $50 \%$ loss in ductile properties.

3. As the internal hydrogen content increases, average ductile properties decrease. There are no appreciable losses in strength associated with increased hydrogen. The presence of inclusions in material with higher hydrogen are more likely to result in premature failure and decreased ductility, especially at lower strain rates. Increasing the strain rate appears to mitigate the deleterious effects of inclusions, thereby resulting in higher ductile properties with less variance. Fracture morphologies associated with slow strain rates and high hydrogen content are characterized by a brittle topography with a mixed mode of predominantly quasi-cleavage and isolated pockets of microvoid coalescence. The fracture path appears to favor propagation along the martensitic platelets. Fracture morphologies of material with low hydrogen content and high strain conditions are characterized by predominantly microvoid coalescence.

\section{REFERENCES}

1) A. M. Ammons, "Precipitation Hardening in Uranium-Rich Titanium Alloys," Physical Metallurgy of Uranium Alloys, J. J. Burke, D. A. Colling, A. E. Gorum, and J. Greenspan, eds., Brook Hill, 1976.

2) K. H. Eckelmeyer and F. J. Zanner, "The Effect of Aging on the Mechanical Behaviors of U-0.75 wt. \% Ti and U-2.0 wt. \% Mo," J. of Metals, Vol. 62, No. 1, p. 37, October 1976.

3) G. L. Powell, "Overview of Hydrogen Embrittlement of Uranium and Uranium Alloys," Metallurgical Technology of Uranium and Uranium Aloys, Vol. 3, p. 877, Union Carbide Corp., Nuciear Division, American Society of Metals, 1982. 
4) American Society for Testing and Materials, Section 3, Metals Test Methods and Analytical Procedures, Vol. 03.01, p. 124, Philadelphia, Pa., 1986.

5) G. M. Ludtka and E. L. Bird, "Heat Treating of Uranium and Uranium Alloys," $A S M$ Metals Handbook, Vol. 4: Heat Treating, p. 928, ASM International, Materials Park, Ohio, 1991.

6) E. A. Steigerwald, F. W. Schaller, and A. R. Troiano, Transactions, TMS-AIME, Vol. 214, p. $1048,1959$.

7) A. R. Troiano, Transactions, ASM, p. 54, 1960.

8) R. L. Schulte, P. N. Adler, and N. E. Paton, "Hydrogen Effects in Metals," Proceedings of Conference, TMS-AIME, p. 177, Warrendale, Pa., 1981.

9) S. L. Robinson, N. R. Moody, J. C. Costa, A. E. Pontau, and W. W. Gerberich, "Hydrogen Isotope Concentration Enhancements at a Blunt Notch," Scripta Metallurgica, Vol. 24, p. 111, 1990.

10) G. M. Pressouyre, J. P. Fidelle, and R. Arnould-Laurent, "Trap Theory of Hydrogen Embrittlement: Experimental Investigations, Hydrogen Effects in Metals," p. 27, Metallurgical Society of AIME, Warrendale, $\mathrm{Pa} ., 1981$. 


\section{Distribution:}

The Univarsity of Tennessee

Materials Science and Engineering Department

Knoxville, Tennessee

Professor C. R. Brooks

Oak Ridge Y-12 Plant

E. L. Bird

A. K. Lee/DOE-OSTI (2)

W. G. Northcull, Jr.

T. H. Thrasher

Y-12 Central Files - RC 

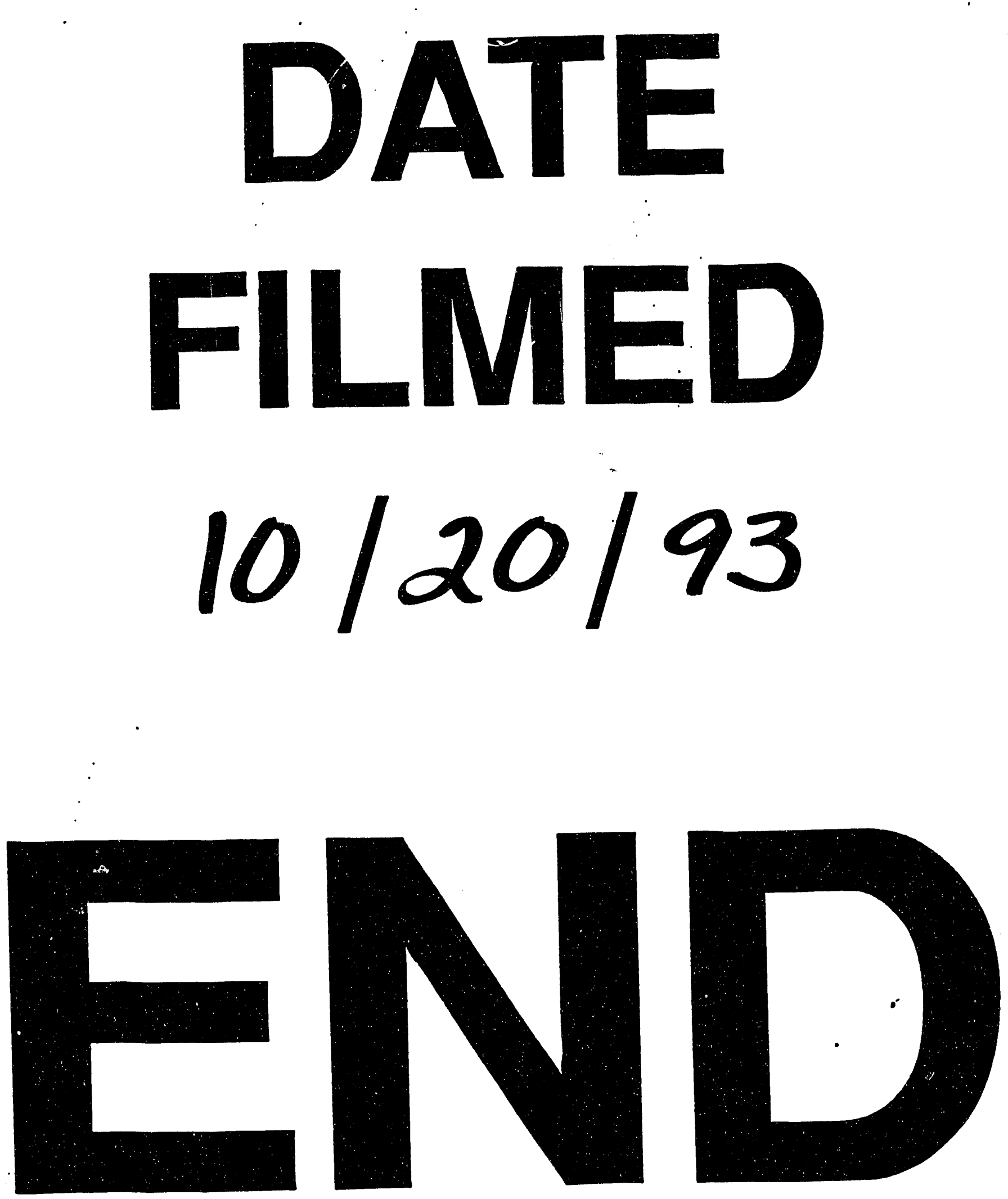
